\title{
Effects of Clothing Pressure Caused by Different Types of Brassieres on Autonomic Nervous System Activity Evaluated by Heart Rate Variability Power Spectral Analysis
}

\author{
Aya Miyatsuji ${ }^{1)}$, Tamaki Matsumoto ${ }^{2)}$, Sachiko Mitarai ${ }^{1)}$, \\ Tetsuro Kotabe ${ }^{1)}$, Takehiro Takeshima ${ }^{1)}$ and Shigeki Watanuki ${ }^{3)}$ \\ 1) Comfort Laboratory, Apparel Division Group, Gunze Limited \\ 2) International Buddhist University \\ 3) Kyushu Institute of Art
}

\begin{abstract}
The present study was designed to investigate the effects of clothing skin pressures exerted by two different types of brassieres (a conventional higher skinpressured brassiere and a newly devised low skinpressured brassiere) on the autonomic nervous system (ANS) activity. Six healthy young women (22.8 \pm 1.4 yrs.) with regular menstrual cycles participated in this study. The ANS activities were assessed by means of heart rate variability power spectral analysis. The skin pressures exerted by the brassieres were measured with an air-pack type contact surface pressure sensor at five different points. The total amount of clothing pressure, and the pressures at the center and the side regions of the brassieres were significantly greater in the high than in the low skin-pressured brassiere (Total 9816.1 \pm 269.0 vs. $6436.8 \pm 252.4 \mathrm{~Pa}, \mathrm{P}<0.01$; Center $2212.1 \pm 336.3$ vs. $353.8 \pm 85.8 \mathrm{~Pa}, \mathrm{P}<0.01$; Side $2556.8 \pm 316.1$ vs. $1747.2 \pm$ 199.2 $\mathrm{Pa}, \mathrm{P}<0.05)$. Concerning the ANS activity, the Total power, and the very low frequency (VLF) and the high frequency (HF) components were significantly decreased in the high skin-pressured brassiere than those in the low skin-pressured brassiere (Total $531.6 \pm 57.3$ vs. $770.5 \pm$ $54.2 \mathrm{~ms}^{2}, \mathrm{P}<0.01$; VLF $60.7 \pm 14.6$ vs. $179.2 \pm 38.1 \mathrm{~ms}^{2}$, $\mathrm{P}<0.05$; HF $209.5 \pm 33.2$ vs. $283.2 \pm 61.5 \mathrm{~ms}^{2}, \mathrm{P}<0.01$ ). Our data indicate that the higher clothing pressures exerted by a conventional brassiere have a significant negative impact on the ANS activity, which is predominantly attributable to the significant decrease in the parasympathetic as well as the thermoregulatory sympathetic nerve activities. Since the ANS activity plays an important role in modulating the internal environment in the human body, excess clothing pressures caused by constricting types of foundation garments on the body would consequently undermine
\end{abstract}

women's health. J Physiol Anthropol 21 (1): 67-74, 2002 http://www.jstage.jst.go.jp/en/

Keywords: clothing pressure, sympathetic nervous system, parasympathetic nervous system, heart rate variability, thermoregulation

\section{Introduction}

The brassiere is one of the most close fitting garments worn by women today. Designed to support and mold the soft tissues of the upper female form, the garment should be shaped to exactly fit the contours of the body. In addition to these requirements, the garment should also be comfortable to wear and aesthetically pleasing.

However, according to a previous poll regarding women's foundation garments, nearly $80 \%$ of women have never been fitted for a brassiere (The British Council et al., 2000). A recent internet-survey conducted by our laboratory has also revealed that approximately $90 \%$ of the 13,000 women responding were not satisfied with their present brassieres and expressed complaints such as discomfort, pain, fatigue, irritation, allergic rashes and/or a sense of tightness. In order to create a better figure, the majority reported wearing a compensatory type of brassier, which gave the appearance of both enlarging and lifting the breasts. Thus, it is assumed that the high garment pressure exerted by a tightly fitting brassier might be a main factor causing discomfort and physical complaints, which consequently could undermine women's health.

The effects of local skin pressure on the physiological function of the human body have been extensively 
Table 1 Anthropometric characteristics of subjects

\begin{tabular}{lcccccccc}
\hline Subjects & $\begin{array}{c}\text { Age } \\
(\mathrm{yrs})\end{array}$ & $\begin{array}{c}\text { Height } \\
(\mathrm{cm})\end{array}$ & $\begin{array}{c}\text { Weight } \\
(\mathrm{kg})\end{array}$ & BMI & $\begin{array}{c}\text { Body fat } \\
(\%)\end{array}$ & $\begin{array}{c}\text { Top bust } \\
(\mathrm{cm})\end{array}$ & $\begin{array}{c}\text { Under bust } \\
(\mathrm{cm})\end{array}$ & Bra size \\
\hline S1 & 24 & 168.0 & 56.0 & 19.8 & 26.5 & 85.0 & 68.5 & D70 \\
S2 & 20 & 152.0 & 43.0 & 18.6 & 22.7 & 79.5 & 66.0 & $\mathrm{C} 70$ \\
S3 & 20 & 159.0 & 45.5 & 18.0 & 21.9 & 82.5 & 66.0 & $\mathrm{C} 70$ \\
S4 & 20 & 153.0 & 45.5 & 19.4 & 20.5 & 82.0 & 69.5 & $\mathrm{C} 70$ \\
S5 & 28 & 158.0 & 47.5 & 19.0 & 19.7 & 79.0 & 67.0 & $\mathrm{C} 65$ \\
S6 & 25 & 153.0 & 46.0 & 19.7 & 20.5 & 82.0 & 70.0 & $\mathrm{C} 70$ \\
\hline Mean \pm SE & $22.8 \pm 1.4$ & $157.2 \pm 2.5$ & $47.3 \pm 1.8$ & $19.1 \pm 0.3$ & $22.0 \pm 1.0$ & $81.7 \pm 0.9$ & $67.8 \pm 0.7$ & \\
\hline
\end{tabular}

investigated. Previous research has verified that skin pressure on specific areas of the body surface decreased the sweating rate (Takagi, 1960; Ogawa et al., 1979; Maruta and Tokura, 1988). Tokura and his group demonstrated that skin pressure exerted by clothing, or artificially applied to the body, suppressed salivary secretion in humans (Tokura, 1989; Okura et al., 2000). A series of recent studies have revealed that skin pressure caused by compensatory foundation garments has an inhibitory influence on gastrointestinal digestive processes (Lee et al., 2000b, Takasu et al., 2000; Sone et al., 2000). According to the investigation of Lee et al. (2000a), skin pressure by foundation garments could also alter the circadian rhythm of the core temperature as well as salivary melatonin. These findings suggest that excess skin pressure applied to the human body could adversely affect the physiological homeostatic mechanisms through altering the autonomic nervous system (ANS), a coordinator of internal environment in the human body.

The beat-to-beat variation in heart rate, termed heart rate variability (HRV), is a well-accepted noninvasive tool for assessing the ANS activity under various physiological conditions (Moritani et al., 1995; Malliani et al., 1998). In general, power spectral analysis of HRV has shown at least two distinct regions of periodicity in electrocardiogram (ECG) R-R intervals. The high frequencies $(\mathrm{HF}>0.15 \mathrm{~Hz})$ of $\mathrm{HRV}$ are associated almost entirely with vagal nerve activity and the low frequencies $(\mathrm{LF}<0.15 \mathrm{~Hz})$ of HRV are mediated by both vagal and sympathetic nervous system (SNS) activities (Akselrod et al., 1981; 1985; Pagani et al., 1986). We have recently demonstrated that very low frequency components (VLF: 0.007-0.035 Hz) were selectively increased in humans against several thermogenic perturbations (Matsumoto et al., 1999; 2000; 2001). These findings indicate that, unlike the other measurements, such as catecholamine concentration and muscle sympathetic nerve activity, the HRV power spectral analysis provides a comprehensive quantitative and qualitative evaluation of integrative thermoregulatory sympathetic as well as global autonomic nervous activities in humans.

To the best of our knowledge, little scientific research has been devoted to examining the psycho-physiological roles of the fashion brassiere. Thus, it would be of interest to explore a possible association between clothing skin pressures, subjective measurements of comfort, a compensatory effect as a foundation garment and the reliable physiological parameters, such as the ANS activity, among different types of brassieres.

In the present study, we focused on evaluating the ANS activity by means of the revised HRV power spectral analysis (Matsumoto et al., 2001) in healthy young women fitted with two different types of brassieres: a conventional higher skin-pressured brassiere and a newly devised low skin-pressured brassiere (Gunze Limited, 2001). The main objective of the present study was to investigate whether excess garment pressure by the higher skin-pressured brassiere would affect the global ANS as well as the thermoregulatory SNS activities.

\section{Methods}

\section{Subjects}

Six healthy young women were recruited for this study. They were all volunteers working in our corporation. Anthropometric characteristics of the subjects are presented in Table 1. Body mass index (BMI) was calculated as body mass divided by height squared, and none of the subjects were overweight $\left(\mathrm{BMI}<25 \mathrm{~kg} / \mathrm{m}^{2}\right)$ (Matsuzawa et al., 2000). Percent of body fat was determined by the bio-electrical impedance analysis method (HBT-300, OMRON, Japan).

The study protocol was approved by the Institutional Review Board of Gunze Limited. All subjects were informed of the nature and purpose of the study, and all gave their informed consent to participate in the study. The subjects completed a standardized health questionnaire for past medical history, medication, lifestyle, diet, smoking habits, alcohol consumption, and physical activity. All subjects were non-smokers in good health and had no evidence of hypertension, cardiovascular disease, diabetes mellitus, or other endocrine diseases. None of the subjects were pregnant, or taking oral contraceptives or any other medication. 
The subjects reported regular menstrual cycles between 28 and 35 days over the previous six months. Considering the possible periodical changes of the ANS activity during the menstrual cycle (Sato et al., 1995; Saeki et al., 1997), experiments were carried out during the follicular stage of each subject. All subjects were weight stable at the time of the study with no more than a two-kg weight loss or gain over the six months before the study. Each subject was instructed to avoid any food or beverages containing alcohol or caffeine after 9:00 p.m. of the day preceding the study.

\section{Experimental brassieres}

Two different types of brassieres were used in the present investigation. One was a conventional high skinpressured brassiere on the market. The other was a newly devised comfort brassiere, which has been designed and manufactured at the Comfort Laboratory of Gunze Limited. This new type of brassier has been developed in part in order to reduce clothing skin pressure on the upper part of the trunk. The physiological functions, structure, design and materials (fabrics, seams, underwire, straps, padding etc.) of the brassiere have been described in detail elsewhere (Gunze Limited, 2001).

\section{Experimental procedure}

The experiments were performed from September to November in 1999. Subjects came to the dormitory adjacent to Gunze Limited at 9:00 p.m. one day before the experiment. It has been reported that the effects of skin pressure from clothing continue for a few hours even after skin pressure is removed (Okura et al., 2000). Thus, each subject changed from her casual wear into a loosefitting experimental nightgown (one-piece with short sleeves and panties), which exerted nearly no skin pressure on the body and then retired for sleep at 10:00 p.m.

On the day of the experiment, the subjects woke up at 6:00 a.m. and were professionally fitted for one of the two different types of brassieres. They wore the brassiere for 6 hours while performing their daily routine. Subjects came to the laboratory at noon, and all experiments were performed in one hour. The room was controlled at an ambient temperature of $25^{\circ} \mathrm{C}$ with a relative humidity of $60 \%$ and quiet with a minimization of arousal stimuli. The subjects were instrumented with ECG electrodes and then rested for at least 10 minutes before the beginning of the experiment. After the resting period, the CM5 lead ECG was continuously recorded while the subject remained seated in a comfortable chair for 20 minutes. All subjects were instructed to breathe in synchrony with a metronome at 15 beats $\cdot \min ^{-1}(0.25 \mathrm{~Hz})$ to ensure that respiratory-linked variations in heart rate did not overlap with low-frequency heart rate fluctuations (below 0.15
$\mathrm{Hz}$ ) from other sources.

The clothing pressure exerted by the brassiere was measured with an air-pack type contact surface pressure sensor (AMI TECHNO. LTD.) at the following five points: the central region of the brassiere (Center), the lowest point of the underwire of the brassier (Low), the lower hem of the side region of the brassiere just under the axillary region (Side), the left side of back under the shoulder strap (Back) and around shoulder strap left above the bust (Shoulder).

Two days later, the same experimental procedure was repeated with the other type of brassiere. The order of the two types of brassieres was randomized to eliminate systematic error.

\section{$R$ - $R$ spectral analysis procedure}

In the present study, a newly invented HRV spectral analysis was utilized to investigate the effects of clothing pressure caused by two different types of brassieres on the ANS activity in healthy young women. The process of developing the new technique of HRV spectral analysis has been fully described in our recent studies (Matsumoto et al., 1999, 2001).

Our R-R interval power spectral analysis procedures have also been mentioned in great detail elsewhere (Moritani et al., 1993; 1995; Hayashi et al., 1994). Briefly, analog output of the ECG monitor (SIGNAL PROCESSOR 1000, NEC) was digitized via a 13-bit analog-to-digital converter at a sampling rate of $1000 \mathrm{~Hz}$. The digitized ECG signal was differentiated, and the resultant QRS spikes and the intervals of the impulses ( $R-R$ intervals) were stored sequentially on a hard disk for later analyses.

Before the R-R spectral analysis was performed, the stored R-R interval data was displayed and aligned sequentially to obtain equally spaced samples with an effective sampling frequency of $2 \mathrm{~Hz}$ (Rompelman et al., 1977) and displayed on a computer screen for visual inspection. Then, the DC component and trend were completely eliminated by digital filtering for the bandpass between 0.007 and $0.5 \mathrm{~Hz}$. The high-pass filtering at $0.007 \mathrm{~Hz}$ was chosen to include the frequency components associated with thermoregulatory functions of the ANS (Matsumoto et al., 2001).

The root mean square value (RMS) of $R$ - $R$ interval was calculated as representing the average amplitude. After passing through the Hamming-type data window, power spectral analysis by means of a fast Fourier transform was then performed on consecutive 1024-sec time series of R$\mathrm{R}$ interval data obtained during the test. To evaluate the ANS activity in each subject of the present study, we analyzed very low frequency (0.016-0.035 Hz, VLF), low frequency (0.035-0.150 Hz, LF), high vagal component (0.150-0.400 Hz, HF) and total power (0.016-0.400 Hz, Total) by integrating the spectrum for the respective band width (Fig. 1). In addition, an index of the global SNS was 


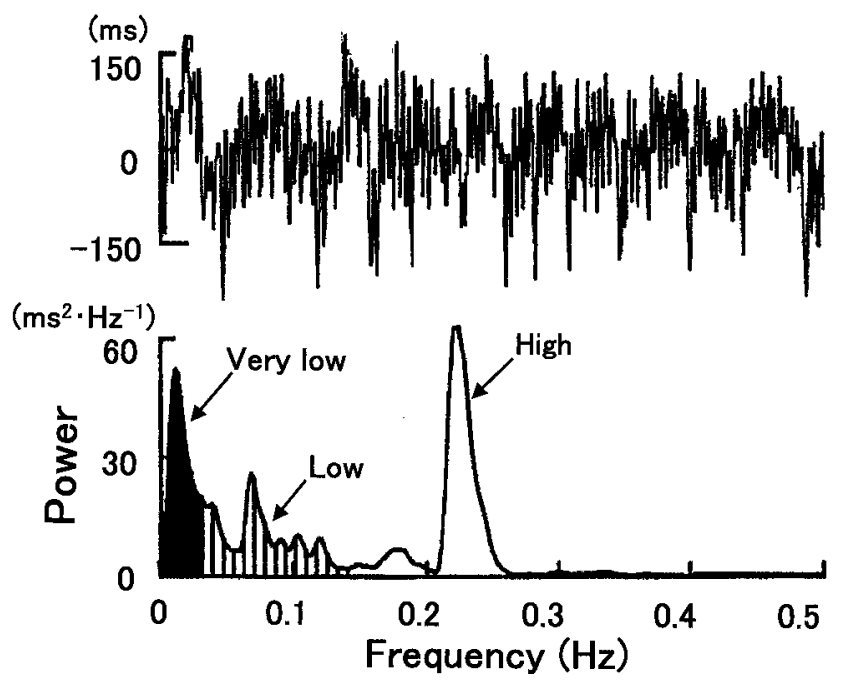

Fig. 1 Examples of ECG R-R interval changes and the corresponding power spectra for a healthy young subject in the resting condition. The technique of heart rate variability power spectral analysis used in the present study identifies three separate frequency components reflecting the sympathetic and parasympathetic as well as thermoregulatory functions. Very low $(0.016-0.035 \mathrm{~Hz})$, low $(0.035-0.150 \mathrm{~Hz})$ and high $(0.150-$ $0.400 \mathrm{~Hz}$ ) frequency components are represented by the black, the vertical line, and the white areas, respectively.

also calculated as the ratio of $\mathrm{LF} / \mathrm{HF}$ according to previous studies (Moritani et al., 1993; 1995; Hayashi et al., 1994). It should be noted that the VLF frequency component was significantly increased in the non-obese healthy young individuals during several thermogenic perturbations, which suggests that the component serves as an indicator for the sympathetic function associated with thermoregulation (Matsumoto et al., 1999; 2000; 2001). Thus, we defined the VLF frequency component as an integrative thermoregulatory SNS activity. The mean heart rate of each 1024-sec segment was also calculated together with standard deviation.

\section{Statistical analyses}

All statistical analyses were performed using a commercial software package (SPSS version 8.0 for Windows, SPSS inc., Illinois). Statistical differences between the two types of brassieres were assessed by mean of a paired $t$-test. $\mathrm{P}$ values $<0.05$ were considered to be statistically significant. Data are expressed as mean \pm SE.

\section{Results}

\section{Clothing pressure}

Figure 2 represents the clothing pressure on the upper part of the body exerted by the two different types of brassieres. The total amount of clothing pressure was

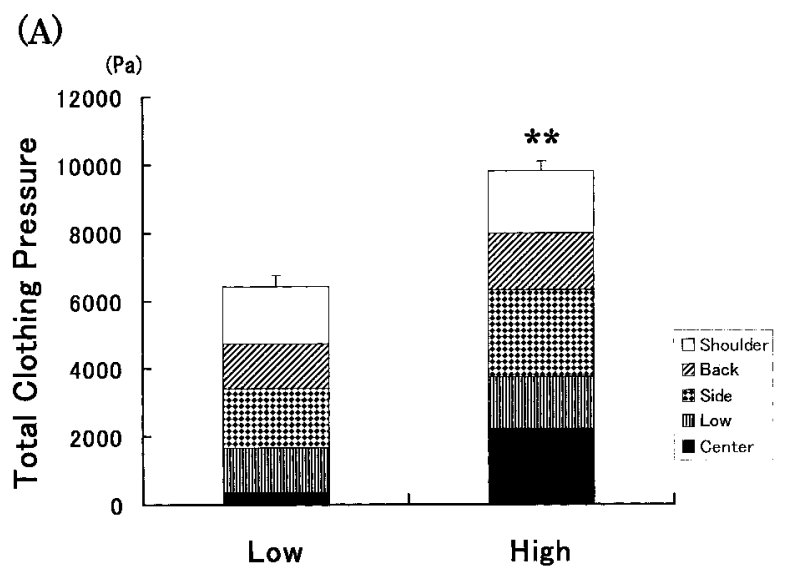

(B)

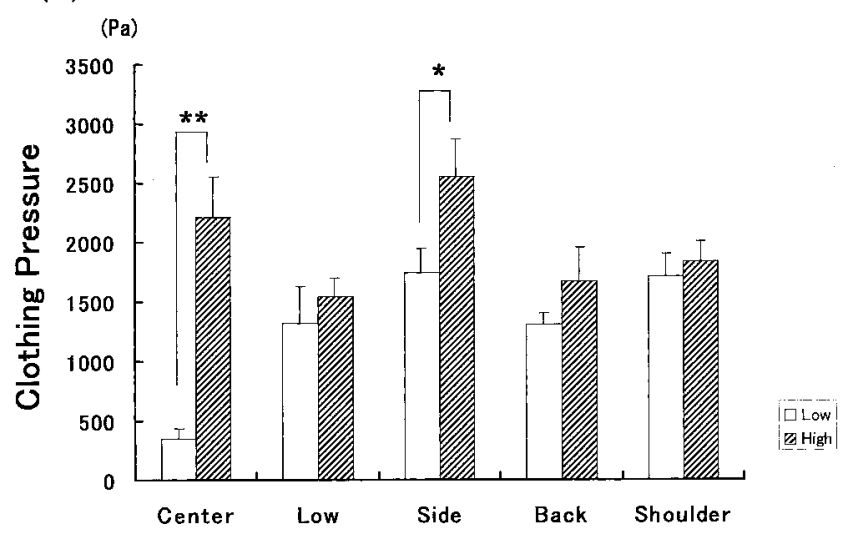

Fig. 2 Comparison of (A) total clothing skin pressure, and (B) the pressures at five different areas of the upper part of the trunk between the newly devised low skin-pressured (Low) and the conventional high skin-pressured (High) brassieres. Results are expressed as mean $\pm \mathrm{SE}$ for each group. ${ }^{*} \mathrm{P}<0.05,{ }^{*} \mathrm{P}<0.01$.

significantly greater in the high than in the low skinpressured brassiere (9816.1 \pm 269.0 vs. $6436.8 \pm 252.4$ pascal $(\mathrm{Pa}), \mathrm{P}<0.01)$ (Fig. $2(\mathrm{~A})$ ). The clothing pressures created by the two brassieres were further compared at five different areas of the upper trunk of the body. As Fig. 2 (B) shows, the high skin-pressured brassiere demonstrated markedly augmented clothing pressures on the Center and the Side regions as compared to the low skin-pressured brassiere (Center: $2212.1 \pm 336.3$ vs. 353.8 $\pm 85.8 \mathrm{~Pa}, \mathrm{P}<0.01$; Side $2556.8 \pm 316.1$ vs. $1747.2 \pm 199.2$ $\mathrm{Pa}, \mathrm{P}<0.05)$. It should be noted that according to our recent Internet survey for approximately 13,000 women who were unintentionally selected, the Center and the Side regions of a brassiere were the most common parts blamed for inducing discomfort such as pain, irritation and/or a sense of tightness. The high skin-pressured brassiere also had greater clothing pressures at the other three regions (Low, Back and Shoulder) as compared to the low skin-pressured brassiere. Differences in these 

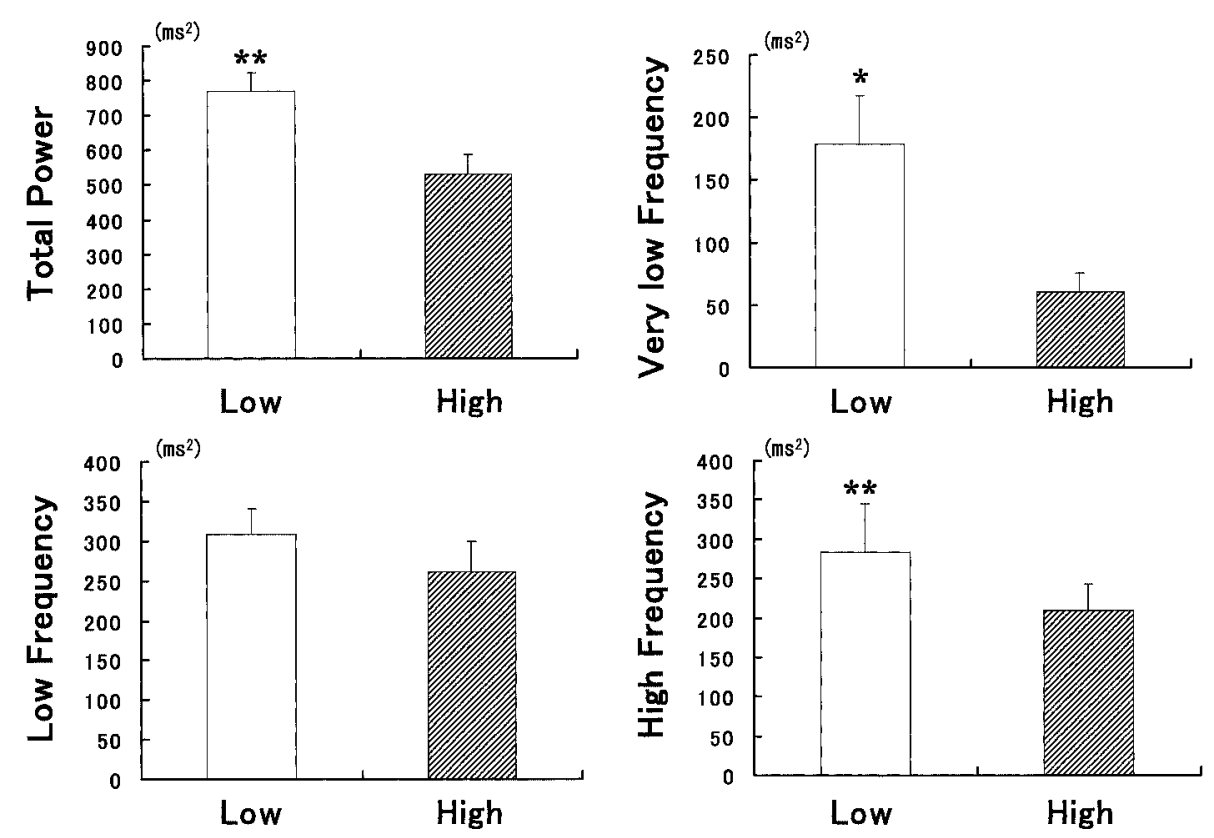

Fig. 3 Comparison of Total Power, and Very Low, Low and High Frequency components between the newly devised low skin-pressured (Low) and the conventional high skin-pressured (High) brassieres. Results are expressed as mean $\pm \mathrm{SE}$ for each group. ${ }^{*} \mathrm{P}<0.05,{ }^{*} \mathrm{P}<0.01$.

pressures, however, did not reach statistical significance between the two types of brassieres (Low: $1540.7 \pm 157.2$ vs. $1314.4 \pm 312.5 \mathrm{~Pa}$; Back $1667.8 \pm 293.2$ vs. $1313.1 \pm$ $90.5 \mathrm{~Pa}$; Shoulder $1838.8 \pm 175.9$ vs. $1708.2 \pm 194.4 \mathrm{~Pa})$.

\section{Autonomic nervous system activity}

Figure 3 represents the R-R power spectral parameters (Total, VLF, LF and HF) obtained from 6 subjects wearing the two different types of brassieres. As the graphs indicate, the Total Power, and the VLF and the HF components were more significantly reduced in the high skin-pressured brassiere than those in the low skinpressured brassiere (Total $531.6 \pm 57.3$ vs. $770.5 \pm 54.2$ $\mathrm{ms}^{2}, \mathrm{P}<0.01$; VLF $60.7 \pm 14.6$ vs. $179.2 \pm 38.1 \mathrm{~ms}^{2}, \mathrm{P}<0.05$; HF $209.5 \pm 33.2$ vs. $283.2 \pm 61.5 \mathrm{~ms}^{2}, \mathrm{P}<0.01$ ). In contrast, the LF component did not statistically differ between the two brassieres ( $209.5 \pm 33.2$ vs. $\left.283.2 \pm 61.5 \mathrm{~ms}^{2}\right)$. The ratio of the LF to the HF components, which has been widely used as the global SNS index in the physiological and clinical research fields, was also calculated in the two types of brassieres. The statistical analysis showed no significant difference in the value of the index between the low and the high skin-pressured brassieres (1.41 \pm 0.36 vs. $1.48 \pm 0.38)$.

\section{Discussion}

The present study provides valuable information regarding physiological effects of garment pressures by a fashion brassiere on the ANS activity in women. We used the revised technique of HRV power spectral analysis, which enabled us to identify three separate frequency components $(\mathrm{VLF} \cdot \mathrm{LF} \cdot \mathrm{HF})$, and examine whether the conventional higher skin-pressured brassiere affected the sympathetic, parasympathetic and/or thermoregulatory functions. Although quantification and interpretation of HRV remain a complex issue (Eckberg, 1997; Conney et al., 1993), the efficacy and applicability of the technique utilized in the present investigation have been shown in previous research (Moritani et al., 1999; Matsumoto et al., 2001). By applying this analysis procedure, we found that the Total Power and, HF and VLF components were markedly reduced in the high skin-pressured brassiere compared to the low skin-pressured brassiere. This finding indicates that a constricting type of fashion brassiere have a significant negative impact on the ANS activity, which is predominantly attributable to the significant decrease in the parasympathetic nervous system (PNS) as well as the thermoregulatory SNS activities.

Although all body systems contribute, the relative stability of human's internal environment depends largely on the orchestrations of the ANS, the system of motor neurons that innervates smooth and cardiac muscles, and glands. Since the ANS is involved in nearly every important homeostatic process going on within the body, it is not surprising that abnormalities of autonomic functioning can have far-reaching effects. 
According to previous research in the field of the clothing science, Okura et al. (2000) have shown that the skin pressures artificially applied to the body decrease the resting salivary flow rate as well as the concentration of amylase. They also found that the digestive time of starch was lengthened under the same condition. As to foundation garments, recent studies have clarified that the skin pressure exerted by a girdle, or even a brassiere, inhibits the defecation activity, which results in decreasing the amount of feces (Lee et al., 2000b; Takasu et al., 2000). The digestive and gastrointestinal system is greatly influenced by the cholinergic tone of the PNS. Thus, these findings suggested that a higher skin pressure applied to the body might suppress the PNS activity, which our data confirmed, and consequently might alter the regulated physiological functions.

Besides digestive and gastrointestinal system, the PNS contributes to the cardiovascular health, and to modulating individual emotional states and relaxation levels. Previous research evaluated the ANS activity of healthy college students by way of the HRV power spectral analysis and demonstrated that the $\mathrm{HF}$ components of the subjects significantly increased during relaxation training (Sakakibara et al., 1994). Dishman et al. (2000) have recently investigated a potential association of the ANS activity, trait anxiety and perceived stress among the physically-fit population. The data of their study have shown the inverse relationship between persistent emotional stress and the normalized HF component of HRV. Another recent study has reported that depressed mood is related to the magnitude of decrease in the $\mathrm{HF}$ component during stressors in healthy subjects (Hughes and Stoney, 2000).

After completing all experiments, we asked each participant about the subjective measurements of comfort of both the high and low skin-pressured brassieres. Consistent with the results of our Internet survey, all the subjects felt more uncomfortable and experienced pain, irritation and a sense of tightness while wearing the high skin-pressured brassiere. Direct information is still scarce regarding an interrelationship among the PNS activity, clothing skin pressure, and emotional and stress levels. Our data together with the previous findings, however, imply that the higher garment pressure exerted by a conventional fashion brassiere might cause mental as well as physical distresses via the blunted PNS activity.

Regarding the effect of skin pressure on the SNS, inconsistent results have been reported. Takagi (1960) previously demonstrated that bilateral skin pressure on the chest wall suppressed the sweating rate and suggested that this phenomenon could be induced by the inhibition of the SNS innervating sweating glands. According to a recent investigation (Lee et al., 2000a), the skin pressure exerted by both girdle and brassiere suppress the urinary secretion of noradrenaline and the nocturnal rise of salivary melatonin, resulting in an increase of rectal temperature. In contrast, Sugimoto (1991) found that skin pressure from a girdle and bodysuit increased the urinary excretion of noradrenaline. The discrepancy found among these studies may be partly attributable to the differences in methodology, including the type of clothing and the skin pressures applied to the body.

The present study has shown that the VLF component markedly decreased while wearing the high skinpressured brassiere. It should be noted that VLF component was selectively and significantly increased in the non-obese healthy young women during the various thermogenic perturbations (Matsumoto et al., 1999; 2000; 2001; Moritani et al., 1999). These results suggest that the component could serve as a reliable index to reflect the integrative thermoregulatory SNS activity. Interestingly, our most recent findings indicate that the VLF component fluctuates as a function of the stage of the menstrual cycle and markedly decreases in the luteal phase (Miyatsuji et al., 2001). It is well known that a number of women suffer from premenstrual syndrome (PMS) occurring in the late luteal phase during their menstrual cycles. PMS is characterized by broad clusters of physiological and psychological symptoms, such as water retention, rough skin, burning sensation, anxiety, irritability, and dysphoric mood (Andrews, 1994). There are several factors associated with autonomic malfunction in women, i.e., stress, irregular life style, malnutrition, and menstruation cycle. Taking all these facts into account, it is speculated that a high skinpressured brassiere could also have adverse effects on the sympatho-thermoregulatory function and further induce unidentified physiological complaints.

In conclusion, we examined the effects of garment pressures exerted by the high and low skin-pressured brassieres on the ANS activity by means of HRV power spectral analysis. Our results indicate that the higher clothing pressures exerted by a conventional brassiere have a significant negative impact on the ANS activity, which is predominantly attributable to the significant decrease in the PNS as well as the thermoregulatory SNS activities. Since the ANS activity plays an important role modulating homeostatic processes within the body, persistent use of constricting types of foundation garments could consequently threaten women's health.

\section{References}

Akselrod S, Gordon D, Ubel FA, Shannon DC, Barger AC, Cohen RJ (1981) Power spectrum analysis of the heart rate fluctuation: a quantitative probe of beat-to-beat cardiovascular control. Science 213: 220-222

Akselrod S, Gordon D, Madwed JB, Snidman NC, Shannon DC, Cohen RJ (1985) Hemodynamic 
regulation: investigation by spectral analysis. Am J Physiol 249 (Heart Circ Physiol 18): H867-H875

Andrews G (1994) Constructive advice for a poorly understood problem: treatment and management of premenstrual syndrome. Prof Nurse 9: 364-370

Conny MA, Louis AA, Jeroen C, Gerard BA, Herman P (1993) Heart rate variability. Ann Intern Med 118: 436447

Dishman RK, Nakamura Y, Garcia ME, Thompson RW, Dunn AL, Blair SN (2000) Heart rate variability, trait anxiety, and perceived stress among physically fit men and women. Int J Psychophysiol 37: 121-133

Eckberg DL (1997) Sympathovagal balance: A critical appraisal. Circulation 96: 3224-3232

Hayashi T, Masuda I, Shinohara M, Moritani T, Nakao K (1994) Autonomic nerve activity during physical exercise and postural change: investigations by power spectral analysis of heart rate variability. Jpn J Biochem Exerc 6: 30-37

Hughes JW, Stoney CM (2000) Depressed mood is related to high-frequency heart rate variability during stressors. Psychosom Med 62: 796-803

Gunze Limited (2001) http://www.fine-p.net/kinou/ kinou.html

Lee YA, Hyun KJ, Tokura H (2000a) The effects of skin pressure by clothing on circadian rhythms of core temperature and salivary melatonin. Chronobiol Int 17 : 783-793

Lee YA, Kikufuji N, Tokura H (2000b) Field studies on inhibitory influence of skin pressure exerted by a body compensatory brassiere on the amount of feces. J Physiol Anthropol Appl Human Sci 19: 191-194

Malliani A, Pagani M, Montano N, Mela GS (1998) Sympathovagal balance: a reappraisal. Circulation 98: 2640-2643

Maruta N, Tokura H (1988) Effects of skin pressure by swimsuit on local sweat rate, respiratory frequency, heart rate and clothing feeling in sedentary women at an ambient temperature of $35^{\circ} \mathrm{C}$. J Home Econ Jpn 39: 607-611

Matsumoto T, Miyawaki T, Ue H, Kanda T, Zenji C, Moritani T (1999) Autonomic responsiveness to acute cold exposure in obese and non-obese young women. Int J Obes 23: 793-800

Matsumoto T, Miyawaki C, Ue H, Yuasa T, Miyatsuji A, Moritani T (2000) Effects of capsaicin-containing yellow curry sauce on sympathetic nervous system activity and diet-induced thermogenesis in lean and obese young women. J Nutr Sci Vitaminol 46: 309-315

Matsumoto T, Miyawaki C, Ue H, Kanda T, Yoshitake Y, Moritani T (2001) Comparison of thermogenic sympathetic response to food intake between obese and non-obese young women. Obes Res 9: 78-85

Matsuzawa Y, Inoue S, Ikeda Y, Sakata T, Saito Y, Sato Y, Shirai K, Ono M, Miyazaki S, Tokunaga K, Fukagawa K,
Yamananouchi K, Nakamura T (2000) New judgments of obesity and diagnostic standards of obese disease in Japan. Journal of Japan Society for the Study of Obesity 6: $18-21$

Miyatsuji A, Matsumoto T, Amano M, Moritani T (2001) Phase-dependent changes of sympatho-vagal activities during the menstrual cycle in young women evaluated by heart rate variability power spectral analysis. AACN Clinical Issues (submitted).

Moritani T, Hayashi T, Shinohara M, Mimasa F, Shibata M (1993) Comparison of sympatho-vagal function among diabetic patients, normal controls and endurance athletes by heart rate spectral analysis. J Sports Med Sci 7: 31-39

Moritani T, Hayashi T, Shinohara M, Mimasa F, Masuda I, Nakao K (1995) Sympatho-vagal activities of NIDDM patients during exercise as determined by heart rate spectral analysis. In Kawamori R, Vranic M, Horton ES, Kubota M eds. Glucose fluxes, exercise and diabetes. Smith-Gordon, Great Britain, 91-96

Moritani T, Matsumoto T, Miyawaki T, Ue H, Zenji C (1999) Effects of capsaicin on sympathetic nervous system activity and diet-induced thermogenesis in lean and obese young women. Proceedings of the fourth annual congress of the European college of sports science, Rome, Italy, 47

Okura K, Midorikawa-Tsurutani T, Tokura H (2000) Effects of skin pressure applied by cuffs on resting salivary secretion. J Physiol Anthropol Appl Human Sci 19: $107-111$

Ogawa T, Asayama M, Ito M, Yoshida K (1979) Significance of skin pressure in body heat balance. Jpn J Physiol 29: 805-816

Pagani M, Lombardi F, Guzzetti S, Rimoldi O, Furlan R, Pizzinelli P, Sandrone G, Malfatto G, Dell'Orto S, Piccaluga E, Turiel M, Baselli G, Cerutti S, Malliani A (1986) Power spectral analysis of heart rate and arterial pressure variabilities as a marker of sympathovagal interaction in man and conscious dog. Circ Res 59: 178-193

Rompelman O, Coenen AJR, Kitney RI (1997) Measurement of heart-rate variability: part 1 comparative study of heart-rate variability analysis methods. Med Biol Eng Comput 15: 233-239

Saeki Y, Atogami F, Takahashi K, Yoshizawa T (1997) Reflex control of autonomic function induced by posture change during the menstrual cycle. J Auton Nerv Syst 66: 69-74

Sakakibara M, Takeuchi S, Hayano J (1994) Effect of relaxation training on cardiac parasympathetic tone. Psychophysiology 31: 223-228

Sato N, Miyake S, Akatsu J, Kumashiro M (1995) Power spectral analysis of heart rate variability in healthy young women during the normal menstrual cycle. Psychosom Med 57: 331-335 
Sone Y, Kato N, Kojima Y, Takasu N, Tokura H (2000) Effects of skin pressure by clothing on digestion and orocecal transit time of food. J Physiol Anthropol Appl Human Sci 19: 157-163

Sugimoto H (1991) Compression of body by clothing: increase in urinary noradrenaline excretion caused by foundation garments. Jpn J Hyg 46: 709-714

Takagi K (1960) Influence of skin pressure on temperature regulation. In: Yoshimura H, Ogata K, Itoh $\mathrm{S}$, eds. Essential problems in climatic physiology. Kyoto, Japan, Nankodo, 212-249

Takasu N, Furuoka S, Inatsugi N, Rutkowska D, Tokura H (2000) The effects of skin pressure by clothing on whole gut transit time and amount of feces. J Physiol Anthropol Appl Human Sci 19: 151-156

The British Council, Campbell E, Cicolini A, Clark J, King
I, McCorquodale D, Aboud A, Hodge S (2000) Inside Out: underwear and style in the UK. Black Dog Publishing Limited, London UK, 114-115

Tokura H (1989) Physiological significance of clothing and human health. In Tokura H, ed. Proceedings of International Symposium of Clothing Comfort Studies in Mt. Fuji. The Japan Research Association for Textile End-Uses Publishing, Osaka, 203-222

Received: October 17, 2001

Accepted: Nobember 28, 2001

Correspondence to: Tamaki Matsumoto, International Buddhist University, 3-2-1 Gakuenmae, Habikino, Osaka 583-8501, Japan

e-mail: tamaki@shitennoji.ac.jp 